\title{
FURTHER PRACTICAL RESOURCES
}

THIS.Institute, "Not quite right" (https://info.thisinstitute.cam.ac.uk/ not-quite-right)

This is a video which is a scenario about a patient who has a stroke. It's played by actors: it focusses on how care can be better organised and the need for research-driven improvements.

NHS England, "The House of Care" (www.england.nhs.uk/ourwork/ clinical-policy/ltc/house-of-care/)

The House of Care model is a framework for care for people living with long-term conditions. It recognises the need for care coordination, emotional and psychological support, predictive rather than reactive services, and multiple comorbidities becoming the norm.

Care Opinion (www.careopinion.org.uk)

Care Opinion is a place where people can share their experience of health or care services. As of July 2020, over 500 organisations were using Care Opinion to listen to what patients, service users and carers are saying. Care Opinion works with health and care providers, commissioners, health boards, regulators, professional bodies, educators, researchers and patient groups.

Point of Care Foundation (www.pointofcarefoundation.org.uk) The Point of Care Foundation works to improve patients' experience of care and to increase support for the staff who work with them. The website contains useful tools (for example, how to use patient experiences for improving services), impactful videos of patient stories and Schwartz rounds, where staff explore honestly and openly instances where care has not been as good as they would have liked to provide. 
Healthtalk (www.healthtalk.org)

Healthtalk provides thousands of videos of patient experiences with lots of different health conditions to help people to understand and prepare for what lies ahead.

Patient Experience Library (www.patientlibrary.net/cgi-bin/library.cgi) The Patient Experience Library provides a patient experience research and evidence database.

Patient Voices (www.patientvoices.org.uk)

Patient Voices use stories to help patients understand their conditions. 